\title{
Interdigital cell death in the embryonic limb is associated with depletion of Reelin in the extracellular matrix
}

\author{
MJ Díaz-Mendoza ${ }^{1}$, CI Lorda-Diez ${ }^{1}$, JA Montero ${ }^{1}$, JA García-Porrero' ${ }^{1}$ and JM Hurlék,1
}

Interdigital cell death is a physiological regression process responsible for sculpturing the digits in the embryonic vertebrate limb. Changes in the intensity of this degenerative process account for the different patterns of interdigital webbing among vertebrate species. Here, we show that Reelin is present in the extracellular matrix of the interdigital mesoderm of chick and mouse embryos during the developmental stages of digit formation. Reelin is a large extracellular glycoprotein which has important functions in the developing nervous system, including neuronal survival; however, the significance of Reelin in other systems has received very little attention. We show that reelin expression becomes intensely downregulated in both the chick and mouse interdigits preceding the establishment of the areas of interdigital cell death. Furthermore, fibroblast growth factors, which are cell survival signals for the interdigital mesoderm, intensely upregulated reelin expression, while BMPs, which are proapototic signals, downregulate its expression in the interdigit. Gene silencing experiments of reelin gene or its intracellular effector Dab-1 confirmed the implication of Reelin signaling as a survival factor for the limb undifferentiated mesoderm. We found that Reelin activates canonical survival pathways in the limb mesoderm involving protein kinase B and focal adhesion kinase. Our findings support that Reelin plays a role in interdigital cell death, and suggests that anoikis (apoptosis secondary to loss of cell adhesion) may be involved in this process.

Cell Death and Disease (2013) 4, e800; doi:10.1038/cddis.2013.322; published online 12 September 2013

Subject Category: Experimental Medicine

In the developing vertebrate limb, the formation of free digits involves massive cell death within the interdigital mesoderm. These zones of cell death have been originally termed interdigital necrotic areas but constitute a classical example of physiological cell death by apoptosis. ${ }^{1}$ Numerous studies have analyzed the molecular cascade activated in the course of the cell death process; however, the mechanisms triggering interdigital tissue regression remain controversial. ${ }^{2-8}$ Local activation of bone morphogenetic protein (BMP) signaling, together with local downregulation of fibroblast growth factor (FGF) signaling, is central in the course of interdigital regression. $^{9-11}$ However, how these signals modify the interdigital tissue to initiate apoptosis is not fully understood. It has been proposed that modifications of the extracellular matrix $^{12}$ and loss of adhesion of the interdigital mesoderm to the surrounding extracellular matrix precedes the activation of intracellular apoptotic machinery. ${ }^{4}$ This mechanism has been termed 'anoikis' and it occurs in both embryonic and tumoral cell death. ${ }^{13,14}$ The identification of compositional changes in the interdigital matrix preceding the onset of cell death may be relevant for understanding the regulation of this degenerative process.

In a systematic analysis of a c-DNA library obtained from the undifferentiated interdigital mesoderm prior to the onset of interdigital necrotic zones (INZ), we identified the presence of the reelin gene. ${ }^{15}$ Reelin is a large matrix glycoprotein thought to be expressed preferentially in the developing brain ${ }^{16}$ where it controls the migration and laminar arrangement of neurons when the cerebral cortex is formed. ${ }^{17}$ Remarkably, Reelin signaling also promotes the survival of different embryonic and adult neuronal populations. ${ }^{18-20}$ In the developing neural system, Reelin binds to integrins ${ }^{21-23}$ as well as specific receptors, including the very-low-density lipoprotein receptor (VLDLR) and apolipoprotein E receptor 2 (ApoER2) inducing the phosphorylation of the intracellular adaptor protein Disabled-1 (Dab-1), ${ }^{24-26}$ which in turn activates downstream effectors involved in cytoskeletal reorganization, cell migration and cell survival. ${ }^{27}$

In this study, we show that Reelin and its intracellular signaling protein DAB-1 are highly expressed in the undifferentiated mesoderm during digit formation and are downregulated in the interdigits preceding the onset of apoptosis. In accordance with a pro-survival role of this signaling pathway, reelin gene expression is upregulated in vivo by local treatment with FGFs which are survival signals for the interdigital mesoderm and down-regulated by BMPs which are pro-apoptotic signals. In addition, the knockdown of reelin or Dab-1 by short hairpin RNA (sh-RNA) transfection

\footnotetext{
${ }^{1}$ Departamento de Anatomía y Biología Celular and IFIMAV, Facultad de Medicina, Universidad de Cantabria, Santander, 39011, Spain

*Corresponding author: JM Hurlé, Departamento de Anatomía y Biología Celular and IFIMAV, Facultad de Medicina, C/ Cardenal Herrera Oria s/n, Santander 39011, Spain. Tel: +34 942 201922; Fax: +34 942 201903; E-mail: hurlej@unican.es

Keywords: embryonic limb; apoptosis; disabled-1; progress zone; Syndactily; extracellular matrix

Abbreviations: FGFs, fibroblast growth factors; BMPs, bone morphogenetic proteins; TGF $\beta$, transforming growth factor $\beta$; Dab-1, disabled-1; FAK, focal adhesion kinase; AKT, protein kinase B; ApoER2, apolipoprotein E receptor 2; PI3K, phosphatidylinositol-3-kinase; INZ, interdigital necrotic zones; AER, apical ectodermal ridge; PZ, progress zone; sh-RNA, short hairpin RNA; CDNA, complementary DNA; HH, Hamburger-Hamilton stages; i.d., incubation day; p.c., post-coitum; TUNEL, terminal deoxynucleotidyl transferase dUTP nick end labeling; DMEM, Dulbecco's modified Eagle's medium; PFA, paraformaldehyde; EDTA, ethylenediaminetetraacetic acid; SDS, sodium dodecyl sulfate; PBS, phosphate-buffered saline; AP, alkaline phosphatase; PI, propidium iodide

Received 17.4.13; revised 08.7.13; accepted 30.7.13; Edited by M Piacentini
} 
increases cell death in primary cultures of the undifferentiated mesoderm. Finally, we identified focal adhesion kinase (FAK) and protein kinase $B(A K T)$ as potential mediators of the pro-survival effect of Reelin signaling.

\section{Results}

Reelin and Dab-1 are highly expressed in the undifferentiated mesoderm prior to the onset of INZ. The reelin gene was identified in a complementary DNA (cDNA) library generated from the interdigital mesoderm of the developing chick limb in the stages preceding cell death. ${ }^{15}$ We cloned reelin and used in situ hybridization to analyze its expression pattern during the formation of the digits in chick and mouse embryos. As shown in (Figures 1a and e), prior to INZ in the chick embryo, reelin exhibited intense expression domains in the undifferentiated mesoderm localized around the tip of the developing digits, as well as in the interdigital regions where cells are healthy and remain undifferentiated. In the following stages, interdigital expression was downregulated preceding the establishment of the areas of interdigital cell death that are responsible for digit freeing (Figures $1 b$ and $f$ ). A gene expression analysis by Q-PCR was used to confirm the intense downregulation of reelin detected by in situ hybridization (Figure 1g). The presence of the Reelin protein
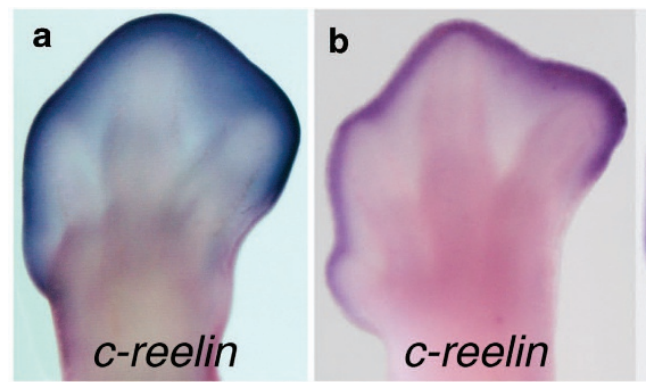

C
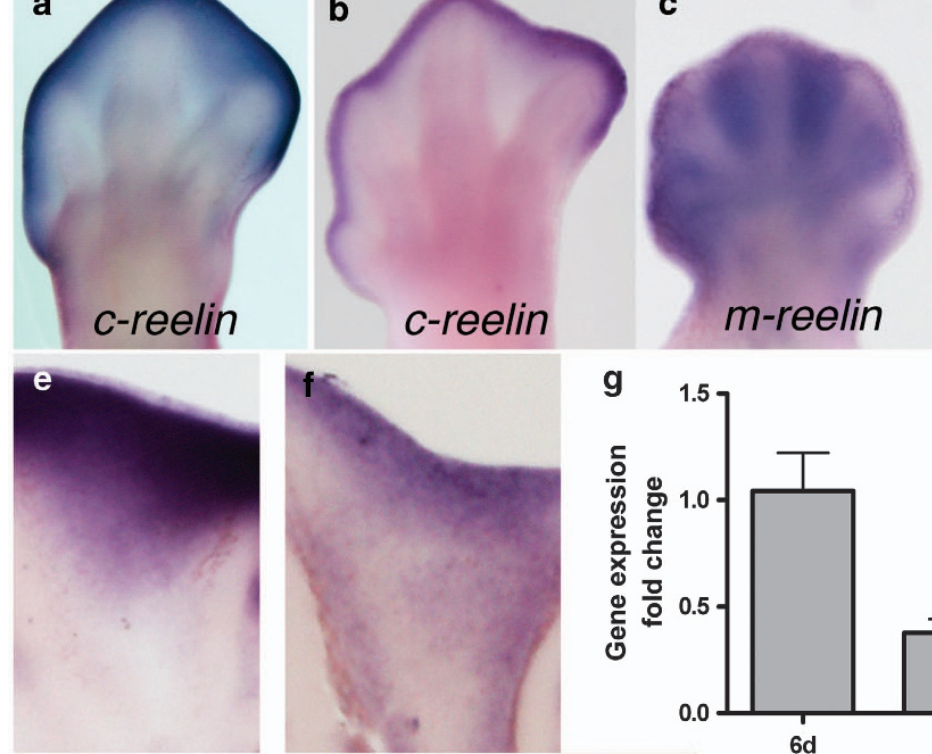

h
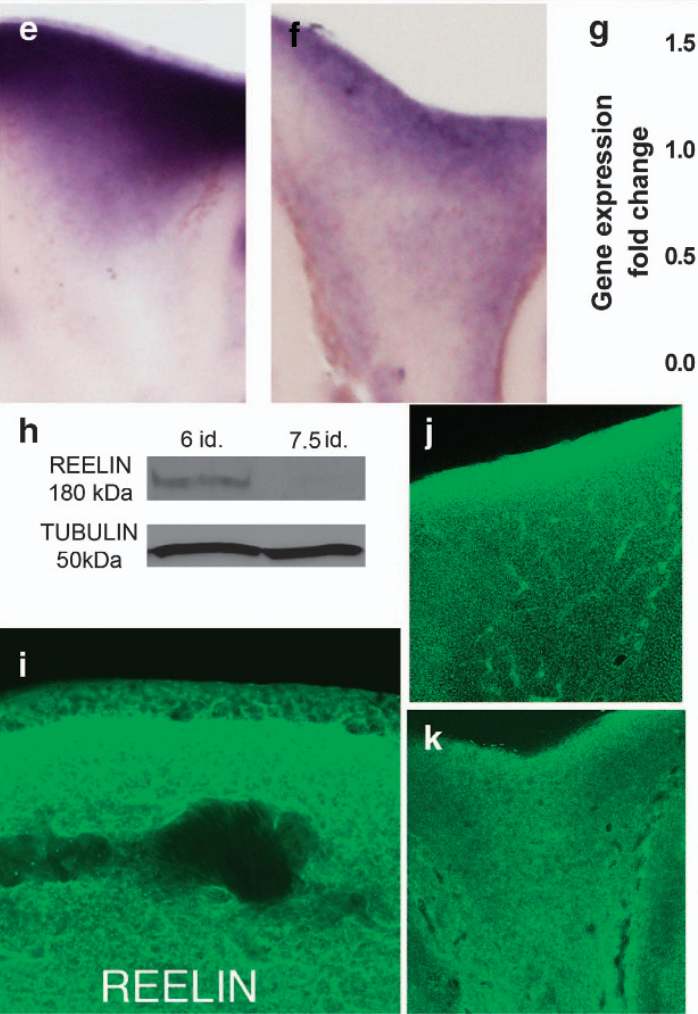

$\mathbf{g}$
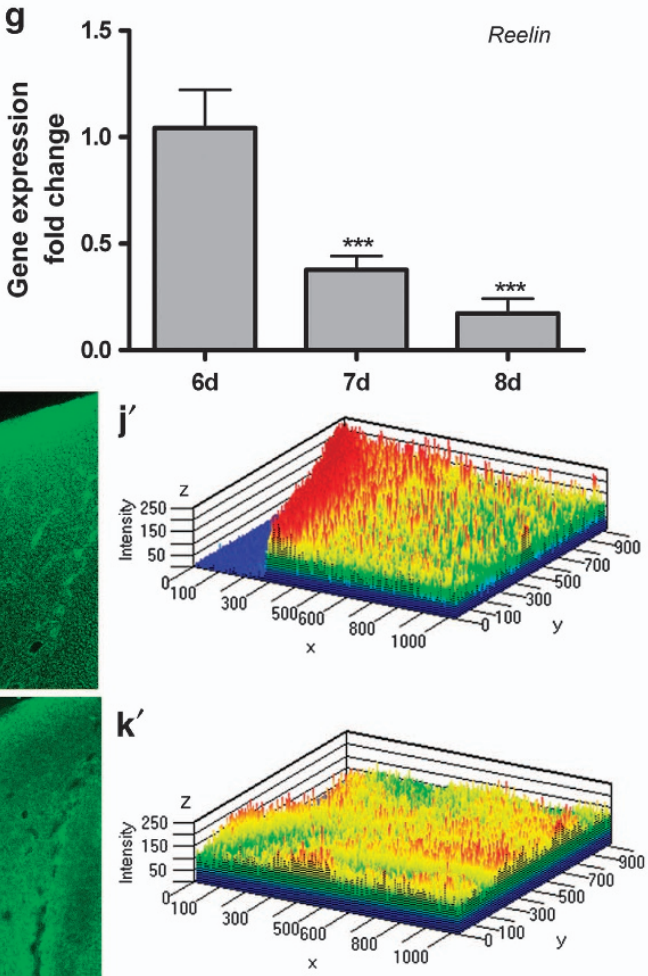

Figure 1 (a and $\mathbf{b}$ ) In situ hybridization illustrating reelin expression in the developing chick autopod at 6 i.d. (a), and 7.5 i.d. (b). Prior to INZ (a) labeling is intense in the interdigital and distal undifferentiated mesoderm. From i.d. 7 , interdigital expression is progressively downregulated (b). (c and d) In situ hybridization of mouse autopods prior to (p.c. day 12.5; c) and at the onset of (p.c. day 13.5; d) INZ. Note the intense labeling in the interdigital mesoderm in (c), and a weaker labeling in (d). (e and f) Detailed views of the third interdigit of chick leg buds to show differences in the intensity of reelin expression at 6 i.d. (e) and 7,5 i.d. (f). (g) QPCR analysis of reelin expression in the interdigital tissue of 6 i.d., 7 i.d. and 8 i.d. embryos. Bars represent gene expression levels in arbitrary units where values are normalized to the expression in the 6 i.d. tissue. ${ }^{\star \star \star} P<0.001$. (h) Representative western blot illustrating differences in Reelin levels in $6 \mathrm{~d} v s$ 7.5d interdigital tissues. (i) Detailed view of a section of the chick autopod at 6 i.d. showing positive Reelin immunolabeling in the distal undifferentiated mesoderm. ( $\mathbf{j}$ and $\mathbf{k}$ ) Low-magnification views of the third interdigit at 6 i.d. (j), and 7.5 i.d. (k) immunostained for Reelin. ( $\mathbf{j}^{\prime}$ and $\mathbf{k}^{\prime}$ ) Surface plots quantifiying the distribution of Reelin immunolabeling in ( $\mathbf{j}$ and $\left.\mathbf{k}\right) . z$ axes $=$ counts of pixel intensity; $x$ and $y$ axes $=$ pixel localization in the corresponding pictures $(\mathbf{j}$ and $\mathbf{k})$. Red and green colors represent higher and lower values, respectively 
in the autopodial tissues (Figure 1i) and its depletion preceding cell death (Figures $1 \mathrm{j}-\mathrm{k}$ ) were also confirmed by western blotting (Figure 1h) and immunolabeling of autopodial vibratome sections monitored by confocal microscopy (Figures $1 \mathrm{j}-\mathrm{j}^{\prime}, \mathrm{k}-\mathrm{k}^{\prime}$ ). Reelin expression was also intense in the interdigits of mouse embryos on day 11 p.c. (Figure 1c). As observed in the chick, expression diminishes in the following stages in relation with the induction of INZ (Figure 1d). Remarkably, in contrast to what was observed in the chick embryo, reelin expression in the distal contour of the autopod was very low. This finding is consistent with the presence of an area of cell death termed 'Sub AER Marginal Zone of cell death' in the mouse autopod that is not present in avians. ${ }^{29}$

Reelin signaling is mediated by phosphorylation of the intracellular adaptor protein DAB-1 upon Reelin binding to its target receptors. Hence, to confirm that this signaling pathway is active during the stages of digit formation, we further analyzed the presence of Dab-1, both at transcriptional and protein level. As shown in Figure 2a, expression of Dab-1 in the undifferentiated mesoderm overlaps with that of reelin At protein level, DAB-1 exhibited a widespread distribution in the undifferentiated interdigital mesoderm (Figure $2 b$ and $d$ ). Specific immunolabeling for phosphorylated DAB-1 (p-DAB-1) confirmed the presence of active signaling in a considerable number of undifferentiated mesodermal cells (Figure 2c).

Regulation of reelin gene expression by FGFs and BMPs. To analyze the possible functions of Reelin in the interdigital mesoderm, we studied reelin gene regulation by growth factors known to regulate interdigital cell death (Figure 3). As shown in Figure 3b, the interdigital expression domain of reelin was extended following FGF-2 overexpression in the undifferentiated limb mesoderm. This treatment has been shown to inhibit interdigital cell death by maintaining mesodermal cells in an undifferentiated state. $^{30}$ By contrast, interdigital overexpression of BMP7 (Figure 3c), which promotes interdigital cell death, ${ }^{31}$ inhibited reelin expression.

The regulations modulated by FGF-2 and BMP-7 treatments were confirmed by Q-PCR (Figures $3 b^{\prime}$ and $c^{\prime}$ ) and altogether these results demonstrate that reelin expression is promoted by canonical limb mesenchymal cell survival factors while it is inhibited by canonical apoptotic inducing cytokines.
Reelin/Dab1 signaling regulates mesodermal cell survival via AKT and FAK. In light of the results described above, we next explored the function of Reelin signaling in programmed cell death. For this purpose, we designed and

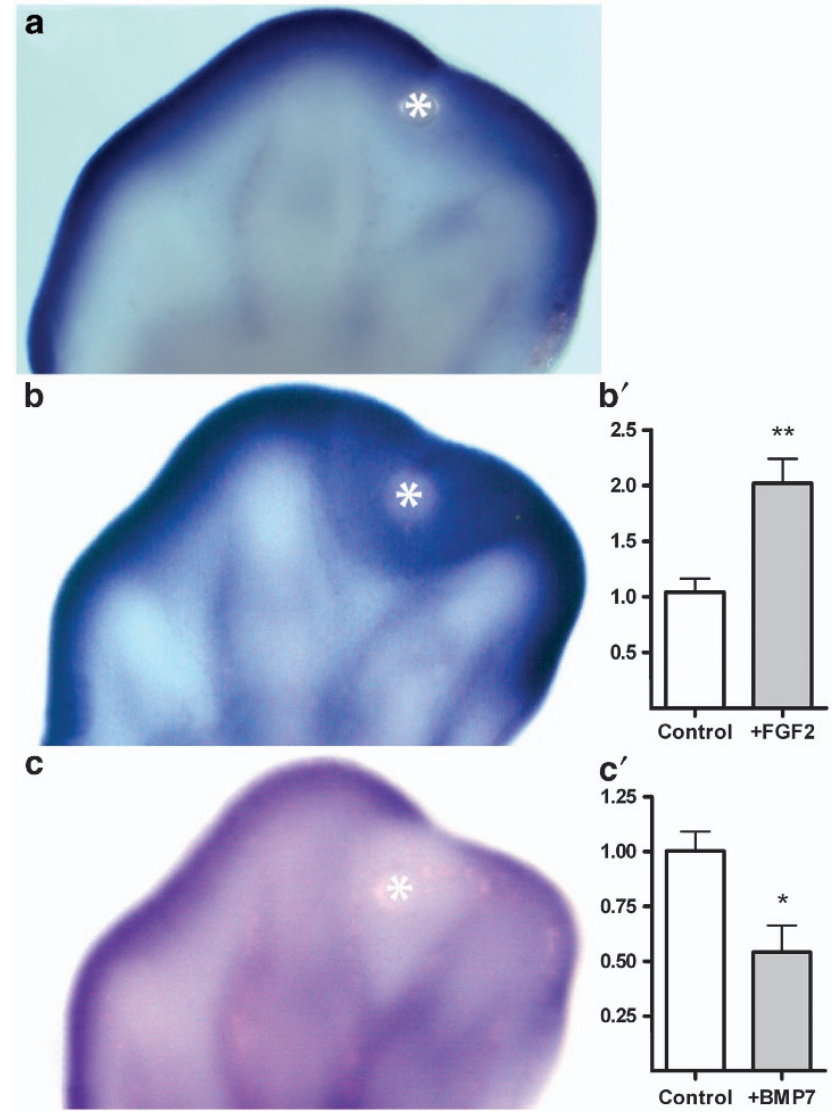

Figure 3 (a-c) Detailed view of reelin expression at 5.5 i.d., $6 \mathrm{~h}$ after interdigital implantation of PBS/BSA-soaked beads (a), FGF2-soaked beads (b), and BMP7-soaked beads (c). Note the upregulation of reelin expression in (b) and the downregulation in (c) in comparison to the control (a). Implanted bead is indicated by $\left(^{*}\right)$. $\left(\mathbf{b}^{\prime}\right)$ QPCR plot showing the positive regulation of reelin in samples of the third interdigit isolated from the autopod $10 \mathrm{~h}$ after FGF-bead implantation. (c') QPCR plots showing reelin downregulation in interdigit explants treated with BMP-7. ${ }^{* \star} P<0.01 ;{ }^{*} P<0.05$
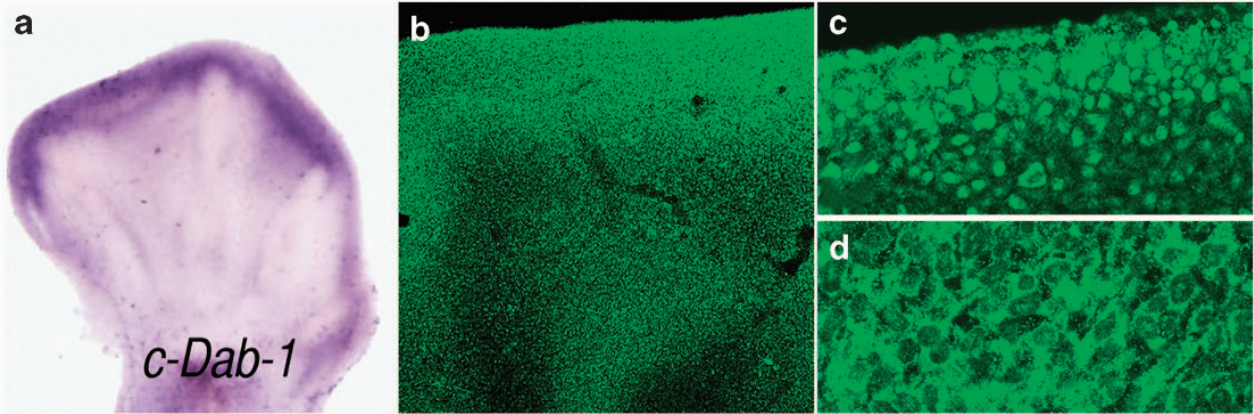

Figure 2 (a) In situ hybridization illustrating Dab-1 expression in a vibratome section of the chick autopod at 7.5 i.d. Note that expression overlaps with that of reelin (b, in Figure 1). (b) Low-magnification view of the third interdigit at 6.5 i.d. immunolabeled with DAB-1. (c and d) Distal undifferentiated mesoderm at 6.5 i.d. showing p-DAB-1 (c) and non-phosphorylated DAB-1 (d) immunolabeling. Note that active signaling as revealed by p-DAB-1 predominates in the distal mesoderm 
transfected shReelin or shDab-1 constructs into undifferentiated mesodermal cells obtained from leg buds on days 4 and 5 of incubation (stage $26 \mathrm{HH}$ ). By Q-PCR and flow cytometry, we observed that the profile of gene regulation and cell death were similar after reelin or Dab-1 silencing, although the effects of the latter were more intense. Hence, we used the shDab-1 construct for subsequent studies. Changes in gene expression induced by $D a b-1$ gene silencing (Figure 4) included downregulation of transforming growth factor $\beta 2$ ( $\operatorname{Tg} f \beta 2)$, which is a triggering signal for digit

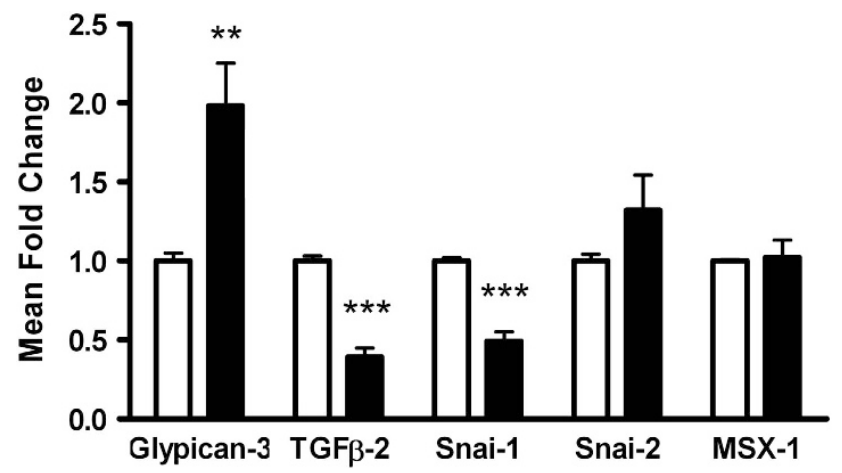

Figure 4 Chart showing the regulation of the Glypican, Tgf $\beta 2$, Msx-1, Snai-1, and Snai-2 genes in 3-day mesodermal cell cultures transfected with shDab-1 (black column) in comparison to control cultures (white column). ${ }^{* * *} P<0.001$; ${ }^{* *} P<0.01$ formation; ${ }^{32}$ upregulation of Glypican 3, a cell surface anchored proteoglycan that inhibits cell proliferation and survival via interactions with several growth factors and adhesion and matrix molecules ${ }^{33,34}$ and downregulation of Snai1, a transcription factor that regulates cell adhesion through the integrin signaling cascade. ${ }^{35}$ The expression of other transcription factors characteristic of the undifferentiated and interdigital mesoderm including Msx1 and Snai2/Slug were not modified.

Changes in cell proliferation or cell death were analyzed by flow cytometry after propidium iodide $(\mathrm{PI})$ staining. Proliferation was not modified in undifferentiated mesoderm that had been subjected to Dab-1 silencing, but cell death increased significantly compared to control mesodermal cells transfected with the empty vector (Figures $5 a-c)$. This increased cell death was confirmed by a terminal deoxynucleotidyl transferase dUTP nick end labeling (TUNEL) assay (Figures $5 \mathrm{~d}-\mathrm{e}$ ). To further analyze whether cell death associated with $D a b-1$ silencing recapitulates the regulatory mechanism responsible for physiological cell death in limb development, we analyzed the changes in protein kinase $B$ (AKT). The maintenance of progress zone (PZ) mesoderm viability and proliferation is associated with the activation of AKT by phosphorylation. ${ }^{36}$ We consistently detected more than $50 \%$ downregulation of AKT phosphorylation in mesodermal cells transfected with shDab-1 (Figure 5f).

Because Reelin signaling is functionally associated with integrins, ${ }^{21-23}$ the modification of gene expression after Dab-1 silencing might well reflect changes in cell adhesion. We have
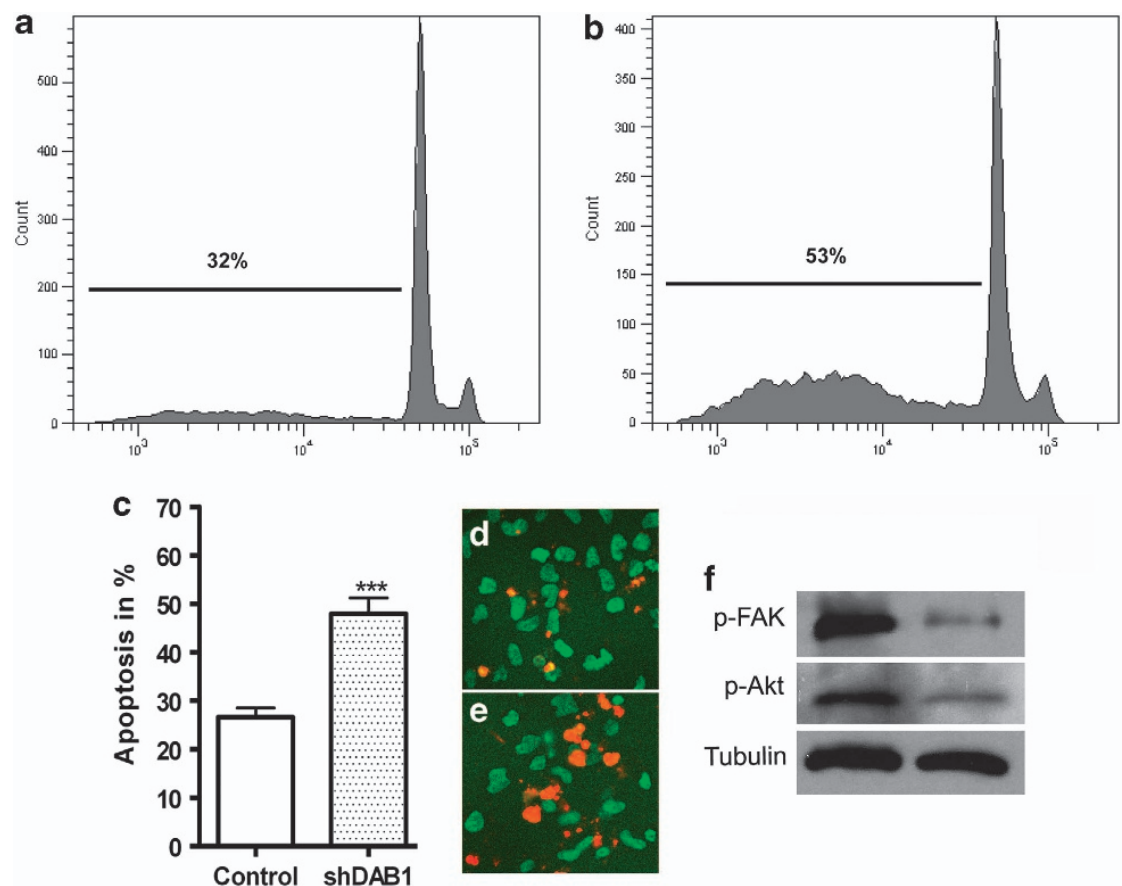

Figure 5 (a) Representative flow cytometry plots of dissociated propidium iodide-stained mesodermal cells indicating an increase in apoptosis in cells transfected with shDab-1 (57\% gene silencing), (b) in comparison to control cells transfected with the empty vector (A). (c) Average difference in the percentage of apoptotic cells in cells transfected with sh-Dab-1 versus control cells as evaluated by flow cytometry ( ${ }^{\star \star *} P<0.001$ ). (d and e) Cell death analysis in undifferentiated limb mesodermal cells in controls (d) and upon Dab-1 gene silencing (e) after immunolabeling for pan-histone (green) and TUNEL (red). (f) Western blot showing the inhibition of FAK and AKT phosphorylation in Dab-1-deficient cultures (right lane) in comparison to control cultures transfected with the empty vector (left lane) 
previously shown that different integrins that are able to bind Reelin, including $\alpha 3, \alpha 5$, and $\beta 1$, are expressed in the undifferentiated limb mesoderm. ${ }^{37}$ Thus, we next explored changes in the integrin-dependent activation of focal adhesion kinase (FAK). As shown in Figure $5 f$, a $60 \pm 8 \%$ reduction in phospho-FAK levels was observed by western blotting of samples obtained from Dab-1 deficient mesodermal precursors.

\section{Discussion}

From the pioneering study of Saunders et al., ${ }^{38}$ which was later confirmed by modern molecular approaches, ${ }^{39}$ it is known that the population of mesodermal cells occupying the distal tip of the limb, known as the $\mathrm{PZ}$, is responsible for distal limb outgrowth. Mesodermal cells within this region are connective tissue progenitors and are maintained in an undifferentiated and proliferative state due to the influence of the apical ectodermal ridge (AER) rimming the distal margin of the bud. Cells undergo differentiation as they move out of the range of $A E R$ signaling. It has been shown that progress zone progenitors require survival factors until they initiate differentiation. ${ }^{40,41}$ Consistent with these observations, when digit primordia are formed, undifferentiated cells that occupy the interdigital spaces suffer massive apoptosis that sculpt the digits from the hand and foot plates. FGFs produced by the AER are considered major survival signals for the undifferentiated limb mesoderm, ${ }^{30}$ while BMPs exert an opposing function that promotes cell death. ${ }^{31}$ Here, we show that Reelin signaling is active in the undifferentiated mesoderm and is downregulated preceding the regression of interdigital tissue in chick and mouse embryos.

Reelin is a large extracellular matrix glycoprotein with putative functions in the embryonic and adult nervous systems; however, increasing information shows that Reelin is also implicated in other systems. ${ }^{42-46}$ Our findings suggest that Reelin contributes to the creation of an extracellular substrate required for maintaining the viability of undifferentiated limb mesodermal cells until they initiate differentiation. In chick limbs, the interdigital expression of reelin is intensely downregulated preceding cell death. Moreover, we observed that reelin is upregulated by a local application of FGFs. These treatments cause the inhibition of interdigital cell death. ${ }^{30}$ In a complementary fashion, local application of BMPs, which are proapototic factors, ${ }^{47}$ downregulates the expression of reelin. Consistent with these findings, disruption of Reelin signaling by silencing Dab-1 increases apoptosis. Markers of the undifferentiated mesoderm such as Msx1 and Snai2/Slug were not regulated. However, the zinc-finger transcription factor Snai $1,{ }^{48}$ which shows the same interdigital expression pattern as reelin and $D a b-1$ in the autopod, ${ }^{30}$ was significantly downregulated. Snai1 contributes to the maintenance of the immature phenotype of stem cells and regulates cell adhesion in the integrin signaling cascade. ${ }^{35}$

Dab-1 is a central component of Reelin signaling. It is phosphorylated by Src family of non-receptor tyrosine kinases ${ }^{26,27}$ after binding of Reelin to its target receptors. Phosphorylated DAB-1 activates intracellular kinases, including Src, phosphatidylinositol-3-kinase (PI3K), the serine/ threonine kinase $\mathrm{AKT}$, and the mitogen-activated protein kinase/extracellular signal-regulated kinase, Erk. ${ }^{25,49,50}$ Although the activity of phosphorylated DAB-1 has been largely associated with the stabilization of the cytoskeleton and regulation of neuronal migration (reviewed by Herz and Chen ${ }^{51}$ ), there is evidence that suggest that some of the neural functions of Reelin are due to the regulation of cell-matrix adhesion via binding to $\alpha 3 \beta 1$ integrin $^{22,23}$ or activation $\alpha 5 \beta 1$ integrin through a biologically conserved inside-out signaling cascade. ${ }^{52}$ In our study, the transcriptional effects of Dab-1 silencing are associated with reduced AKT and FAK phosphorylation, supporting a role for Reelin/ Dab-1 signaling in the promotion of cell-matrix adhesion via integrins. FAK is a major downstream effector of integrin signaling and is implicated in the formation of the prechondrogenic aggregates. ${ }^{53-55}$ Furthermore, the activation of AKT accounts for the pro-survival influence of FGFs in the developing limb. ${ }^{36}$ Both FAK and AKT have been identified as key targets of cell death by anoikis. ${ }^{56}$ Together, these findings suggest that the disruption of Reelin signaling in the mesodermal tissue is followed by reduced integrin-mediated cell adhesion. Many different integrins, including $\alpha 3, \alpha 5$, and $\beta 1$, are expressed in digit progenitors. ${ }^{37}$ Integrins recognize various extracellular matrix components that are abundant in the developing limb, and deficiencies in some of these components are associated with syndactylous mice phenotypes. ${ }^{57,58}$ This fact makes it difficult to establish the relative importance of Reelin in the regression of the interdigital tissue. Mice deficient in reelin or Dab-1 (Reeler or Yotari mutants, respectively) lack the syndactylous phenotype, ${ }^{59}$ suggesting functional redundancy of Reelin with other matrix molecules present in the embryonic limb. In addition, it must be taken into account that the absence of Reelin in mice mutants occurs through the entire embryonic development and not in a small window of time analyzed in our in vitro experiments. Furthermore, predicting protein-protein interactions by a computational algorithm based on structural, functional, and evolutionary data (http://bhapp.c2b2.columbia.edu/PrePPI ${ }^{60}$ ) identifies more than 100 matrix and regulatory molecules expressed in the developing limb that are likely to interact with Reelin. Our findings, together with these observations, suggest that Reelin, while not strictly necessary, contributes to sustain the anchoring of the undifferentiated mesoderm to the extracellular matrix to prevent anoikis.

\section{Materials and Methods}

In this work, we employed Rhode Island chicken embryos from 4.5 to 8 days of incubation (i.d.), which were equivalent to stages 25 to $36 \mathrm{HH}$ and C57BL6 mouse embryos ranging from 11 to 14 days post coitum (p.c.).

In situ hybridization. In situ hybridization was performed in whole-mount specimens and vibratome tissue sections. Samples fixed in 4\% paraformaldehyde (PFA) were treated with $10 \mu \mathrm{g} / \mathrm{ml}$ of proteinase $\mathrm{K}$ for $20-30 \mathrm{~min}$ at $20^{\circ} \mathrm{C}$. Hybridization with digoxigenin-labeled antisense RNA probes was performed at $68^{\circ} \mathrm{C}$. Alkaline phosphatase-conjugated anti-digoxigenin antibody (dilution 1:2000) was used (Roche Applied Science, Indianapolis, IN, USA). Reactions were developed with the BM Purple AP Substrate precipitating solution (Roche Applied Science).

The probes for reelin and Dab-1 were obtained by PCR: chick Reelin $5^{\prime}$-CCTAACAATCGCAACCAAGG-3' and 5'-AGCCTTCTGTTGGAGTCAGG-3'; for mouse reelin $5^{\prime}$-AACACAGTCCATGCAGATCG-3' and $5^{\prime}$-CTTCCTGCCA GTCTGATTCC-3'; for chick Dab-1 5'-AACCTGTGATTCTGGACTTGC-3' and 5'-TGAACAAGTGGTTGCTGTCC-3'. 
In vivo gene regulation analysis was performed in the embryonic chick by whole-mount in situ hybridization following interdigital implantation at 5.5 i.d. of heparin beads (Sigma-Aldrich, St Louis, MO, USA) incubated for $1 \mathrm{~h}$ in $0.5 \mathrm{mg} / \mathrm{ml}$ FGF2 (PeproTech, Rocky Hill, NJ, USA) or $0.5 \mathrm{mg} / \mathrm{ml} \mathrm{BMP-7} \mathrm{(R \& D} \mathrm{Systems,}$ Minneapolis, MN, USA). The contralateral left limb or limbs treated with beads incubated in phosphate-buffered saline (PBS) were used as controls. After manipulation, the eggs were sealed and further incubated until processing.

Mesodermal cultures. Undifferentiated mesodermal cells obtained from the region located under the AER of chick leg buds at 4.5 i.d. (25 HH) were suspended in medium DMEM (Dulbecco's modified Eagle's medium) with $10 \%$ fetal bovine serum, 100 units $/ \mathrm{ml}$ penicillin and $100 \mu \mathrm{g} / \mathrm{ml}$ streptomycin. Cells were seeded on fibronectin-coated coverglasses and were grown as monolayers or cultured at a high density as micromass cultures.

Micromass cultures were made by pipetting $10-\mu$ drops of cell suspension at a density of $2.0 \times 10^{7}$ cells $/ \mathrm{ml}$ into each well of a 24-well plate. The cells were left to attach for $2 \mathrm{~h}$ and then $200 \mu \mathrm{l}$ serum-free medium was added.

Micromasses were used to analyze cell proliferation and cell death in mesodermal cells subjected to reelin signaling knockdown. Monolayer cultures were used for TUNEL assay to detect cell death.

Quantitative analysis of reelin regulation by BMPs was performed in interdigital explants cultured for $5 \mathrm{~h}$ in presence of $0.6 \mu \mathrm{g} / \mathrm{ml}$ of BMP7.

Immunolabeling and TUNEL assay. Samples were fixed with $4 \%$ PFA $\mathrm{O} / \mathrm{N}$ at $4{ }^{\circ} \mathrm{C}$, washed with $0.1 \%$ Triton/PBS and incubated $\mathrm{O} / \mathrm{N}$ at $4{ }^{\circ} \mathrm{C}$ with the primary antibody. Specimens were next washed with PBS, incubated O/N with the secondary antibody, washed for $2 \mathrm{~h}$ with PBS, dehydrated and cleared. Anti-Reelin (SC-5578, Santa Cruz Biotechnologies, Santa Cruz, CA, USA), anti-phospho-DAB-1 (SC-133292, Santa Cruz Biotechnologies) and anti-Dab1 (SC-7827, Santa Cruz Biotechnologies) polyclonal antibodies were used.

Samples were monitored by confocal microscopy, and analysis of immunolabeling intensity was performed measuring pixel intensity distribution using the LSM 5 Image Examiner software (LSM Software Zeiss, Oberkochen, Germany).

TUNEL was performed using the in situ cell death detection kit (Roche Applied Science) according to the manufacturer's instructions.

Cell nucleofection and target gene silencing. Functional studies were performed in chick embryos by a loss-of-function approach. For this purpose, limb mesodermal cells were transfected with a short hairpin RNAi for reelin (shreelin) or Dab-1 (shDab-1) and cloned into the pcU6-1-shRNA (a generous gift of Dr Tim J Doran) as described by Wise et al. ${ }^{28}$ The level of gene silencing was evaluated by Q-PCR and samples with a reduction in gene expression ranging between $45 \%$ and $60 \%$ were selected for further studies. Control transfections using a chU6-1v irrelevant control plasmid were performed in all experiments.

Western blot. For western blot analysis, total protein extracts were obtained from control and shDab-1 silenced mesodermal cultures or interdigital tissues at different stages. Cell lysis was performed with RIPA buffer $(150 \mathrm{mM} \mathrm{NaCl}, 1.5 \mathrm{mM}$ $\mathrm{MgCl}_{2}, 10 \mathrm{mM} \mathrm{NaF}, 10 \%$ glycerol, $4 \mathrm{mM}$ ethylenediaminetetraacetic acid (EDTA), $1 \%$ Triton X-100, $0.1 \%$ sodium dodecyl sulfate (SDS), $1 \%$ deoxycholate and $50 \mathrm{mM}$ Hepes, pH 7.4) supplemented with the protease inhibitors phenylmethylsulfonyl fluoride (PMSF, $1 \mathrm{mM})$, leupetin $(10 \mu \mathrm{g} / \mathrm{ml})$ and aprotinin $(10 \mu \mathrm{g} / \mathrm{ml})$, for $15 \mathrm{~min}$ on ice. The cell lysates were clarified of cellular debris by centrifugation $(13200 \times g)$ for $10 \mathrm{~min}$ at $4{ }^{\circ} \mathrm{C}$. Proteins were separated by $8-10 \%$ polyacrilamide gel electrophoresis containing $0.1 \%$ SDS and transferred to nitrocellulose membrane (Protan; Whatman, Dassel, Germany). The membranes were incubated for $1 \mathrm{~h}$ at room temperature in bovine serum albumin and incubated overnight with the following antibodies: rabbit polyclonal antibody anti-phospho-Akt (SC-1011629, Santa Cruz Biotechnologies), anti-Reelin (SC-5578, Santa Cruz Biotechnologies) and anti-phospho-FAK Y576 (Abcam, Cambridge, UK; ab-4815), and mouse polyclonal antibody anti-tubulin (Sigma-Aldrich, T5168). Protein bands were detected in the membranes with an ODYSSEY infrared-imaging system (LI-COR Biosciences, Lincoln, NE, USA) according to ODYSSEY western blot protocol. Immunoblots were monitored using anti-mouse IRDye $800 \mathrm{DX}$ or anti-rabbit IRDye 680DX (Rockland Immunochemicals, Inc., Gilbertsville, PA, USA). The public domain image analysis program 'ImageJ' was employed to perform quantitative analysis.

Flow cytometry. Cell proliferation and cell death was deduced from measurement of DNA content by flow cytometry. Control and shreelin or
shDab-1 silenced cultures were dissociated to single-cell level by treatment with Trypsin EDTA (Lonza, Basel, Switzerland). One million cells were used in each test. For PI staining, the cells were washed twice in PBS and centrifuged at $405 \times g$ for 5 min at $4^{\circ} \mathrm{C}$. The samples were then incubated overnight at $4^{\circ} \mathrm{C}$ with $0.1 \%$ sodium citrate, $0.01 \%$ Triton X-100 and $0.1 \mathrm{mg} / \mathrm{ml} \mathrm{PI}$. Cell suspension was subjected to flow cytometry analysis in a Becton Dickinson FacsCanto cytometer (BD Biosciences, San Jose, CA, USA) and analyzed with Cell Quest software (BD Biosciences). This technique allows the quantification of apoptotic (hypodiploid) and proliferating (hyperdiploid) cells according to their DNA content deduced from PI staining.

Real time quantitative PCR (Q-PCR) for gene expression analysis. Total RNA was extracted and cleaned from specimens using the RNeasy Mini Kit (Qiagen, Hilden, Germany). RNA samples were quantified using a spectrophotometer (NanoDrop Technologies, Wilmington, DE, USA). Firststrand CDNA was synthesized by reverse transcription-PCR (RT-PCR) using random hexamers, and M-MulV reverse transcriptase (Fermentas GmbH, St Leon-Rot, Germany). The cDNA concentration was measured in a spectrophotometer (NanoDrop Technologies) and adjusted to $0.5 \mu \mathrm{g} / \mu \mathrm{l}$. Q-PCR was performed using the Mx3005P system (Stratagene Inc., La Jolla, CA, USA) with automation attachment. In this work, we have used SYBRGreen (TaKaRa Inc., Otsu, Japan) based Q-PCR. Gapdh had no significant variation in expression across the sample set and therefore was chosen as the normalizer in our experiments. Mean values for fold changes were calculated for each gene. Expression level was evaluated relative to a calibrator according to the $2^{-(\Delta \Delta \mathrm{Ct})}$ equation. Each value in this work represents the mean \pm standard error of the mean of at least three independent samples obtained under the same conditions. Samples consisted of 4 micromass cultures or 20 interdigital spaces. Data were analyzed using one-way analysis of variance followed by Bonferroni tests for post-hoc comparisons for gene expression levels in treated micromass cultures and Student's $t$ test for gene expression levels in overexpression and silencing experiments. Statistical significance was set at $P<0.05$. All the analyses were done using SPSS for Windows version 18.0. Q-PCR specific primers for chick genes were: for Glypican $35^{\prime}$-GGAGAAGTACCAGGCAGTGG-3' and 5'-CAGCATTCTGGATGACAAGG-3'; for Tgf $325^{\prime}$-TGCACTGCTATCTCCTGAGC- $3^{\prime}$ and $5^{\prime}$-GCATGAACTGATCCA TGTCG-3'; for Msx $1^{\prime} 5^{\prime}$-CAAGCACAAGACCAACAGGA-3' and $5^{\prime}$-TACTGCT TCTGGCGGAATTT-3'; for Snai2/Slug 5'-ATACCGCAGCCAGAGATCC-3' and 5'-AGCGGAGAGAGGTCATTGG-3'; for Snai1/Snail $5^{\prime}$-TGCGAGAAGGAGTA TGTGAGC- $3^{\prime}$ and $5^{\prime}$-GCACATCTTGCAGACACAGG- $3^{\prime}$; for reelin $5^{\prime}$-GCACAGT GACAGCATCATCC-3' and $5^{\prime}$-GCTCTCCAATCTCACAGTTGC-3'; for Dab1 5'-AACCTGTGATTCTGGACTTGC-3' and 5'-ATACCGCCTGTTCACACTGC- $3^{\prime}$.

\section{Conflict of Interest}

The authors declare no conflict of interest.

Acknowledgements. We would like to thank Montse Fernandez-Calderon, Sonia Perez-Mantecón and Susana Dawalibi for excellent technical assistance. Thanks are also due to Drs Eduardo Soriano Lluis Pujadas and Ana Illundain for reagents and advice. This work was supported by a grant from the Spanish Ministry of Economy and Competitiveness to JMH (BFU2011-24169). M J D-M is a recipient of a predoctoral FPI fellowship from the Spanish Ministry of Economy and Competitiveness.

1. Garcia-Martinez V, Macias D, Ganan Y, Garcia-Lobo JM, Francia MV, Fernandez-Teran MA et al. Internucleosomal DNA fragmentation and programmed cell death (apoptosis) in the interdigital tissue of the embryonic chick leg bud. J Cell Sci 1993; 106(Pt 1): 201-208.

2. Arteaga-Solis E, Gayraud B, Lee SY, Shum L, Sakai L, Ramirez F. Regulation of limb patterning by extracellular microfibrils. J Cell Biol 2001; 154: 275-281.

3. Rodriguez-Leon J, Merino R, Macias D, Ganan Y, Santesteban E, Hurle JM. Retinoic acid regulates programmed cell death through BMP signalling. Nat. Cell Biol 1999; 1: 125-126.

4. Zuzarte-Luis V, Berciano MT, Lafarga M, Hurle JM. Caspase redundancy and release of mitochondrial apoptotic factors characterize interdigital apoptosis. Apoptosis 2006; 11: 701-715.

5. Montero JA, Lorda-Diez Cl, Certal AC, Moreno N, Rodriguez-Leon J, Torriglia A et al. Coordinated and sequential activation of neutral and acidic DNases during interdigital cell death in the embryonic limb. Apoptosis 2010; 15: 1197-1210. 
6. Ren D, Tu HC, Kim H, Wang GX, Bean GR, Takeuchi $\mathrm{O}$ et al. BID, BIM, and PUMA are essential for activation of the BAX- and BAK-dependent cell death program. Science 2010 330: $1390-1393$.

7. Hernandez-Martinez R, Covarrubias L. Interdigital cell death function and regulation: new insights on an old programmed cell death model. Dev. Growth Differ 2011; 53: 245-258.

8. Aizawa R, Yamada A, Suzuki D, limura T, Kassai H, Harada T et al. Cdc42 is required for chondrogenesis and interdigital programmed cell death during limb development. Mech Dev 2012; 129: 38-50

9. Zou H, Niswander L. Requirement for BMP signaling in interdigital apoptosis and scale formation. Science 1996; 272: 738-741.

10. Hernandez-Martinez R, Castro-Obregon S, Covarrubias L. Progressive interdigital cell death: regulation by the antagonistic interaction between fibroblast growth factor 8 and retinoic acid. Development 2009; 136: 3669-3678.

11. Wong YL, Behringer RR, Kwan KM. Smad1/Smad5 signaling in limb ectoderm functions redundantly and is required for interdigital programmed cell death. Dev Biol 2012; 363: 247-257.

12. McCulloch DR, Nelson CM, Dixon LJ, Silver DL, Wylie JD, Lindner V et al. ADAMTS metalloproteases generate active versican fragments that regulate interdigital web regression. Dev Cell 2009; 17: 687-698.

13. Grossmann J, Walther K, Artinger M, Kiessling S, Scholmerich J. Apoptotic signaling during initiation of detachment-induced apoptosis ("anoikis") of primary human intestinal epithelial cells. Cell Growth Differ 2001; 12: 147-155.

14. Ioannides AS, Massa V, Ferraro E, Cecconi F, Spitz L, Henderson DJ et al. Foregut separation and tracheo-oesophageal malformations: the role of tracheal outgrowth, dorsoventral patterning and programmed cell death. Dev Biol 2010; 337: 351-362.

15. Zuzarte-Luis V, Montero JA, Rodriguez-Leon J, Merino R, Rodriguez-Rey JC, Hurle JM. A new role for BMP5 during limb development acting through the synergic activation of Smad and MAPK pathways. Dev Biol 2004; 272: 39-52.

16. D'Arcangelo G, Nakajima K, Miyata T, Ogawa M, Mikoshiba K, Curran T. Reelin is a secreted glycoprotein recognized by the CR-50 monoclonal antibody. J Neurosci 1997; 17: 23-31.

17. Soriano E, Del Rio JA. The cells of cajal-retzius: still a mystery one century after. Neuron 2005; 46: 389-394.

18. Beffert U, Nematollah Farsian F, Masiulis I, Hammer RE, Yoon SO, Giehl KM et al. ApoE receptor 2 controls neuronal survival in the adult brain. Curr Biol 2006; 16: 2446-2452.

19. Ohkubo N, Vitek MP, Morishima A, Suzuki Y, Miki T, Maeda N et al. Reelin signals survival through Src-family kinases that inactivate BAD activity. J Neurochem 2007; 103: $820-830$

20. Peterziel H, Sackmann T, Strelau J, Kuhn PH, Lichtenthaler SF, Marom K et al. F-spondin regulates neuronal survival through activation of disabled-1 in the chicken ciliary ganglion. Mol. Cell. Neurosci 2011; 46: 483-497.

21. Sanada K, Gupta A, Tsai LH. Disabled-1-regulated adhesion of migrating neurons to radia glial fiber contributes to neuronal positioning during early corticogenesis. Neuron 2004; 42 : 197-211.

22. Dulabon L, Olson EC, Taglienti MG, Eisenhuth S, McGrath B, Walsh CA et al. Reelin binds alpha3beta1 integrin and inhibits neuronal migration. Neuron 2000; 27: 33-44

23. Schmid RS, Jo R, Shelton S, Kreidberg JA, Anton ES. Reelin, integrin and DAB interactions during embryonic cerebral cortical development. Cereb Cortex 2005; 15 1632-1636.

24. Arnaud L, Ballif $B A$, Forster $E$, Cooper JA. Fyn tyrosine kinase is a critical regulator of disabled-1 during brain development. Curr. Biol 2003; 13: 9-17.

25. Bock HH, Herz J. Reelin activates SRC family tyrosine kinases in neurons. Curr Biol 2003, 13: $18-26$.

26. Kuo G, Arnaud L, Kronstad-O'Brien P, Cooper JA. Absence of Fyn and Src causes a reeler-like phenotype. J. Neurosci 2005; 25: 8578-8586.

27. Frotscher M, Chai X, Bock HH, Haas CA, Forster E, Zhao S. Role of Reelin in the development and maintenance of cortical lamination. J Neural Transm 2009; 116: 1451-1455.

28. Wise TG, Schafer DJ, Lambeth LS, Tyack SG, Bruce MP, Moore RJ et al. Characterization and comparison of chicken U6 promoters for the expression of short hairpin RNAs. Anim Biotechnol 2007; 18: 153-162.

29. Fernandez-Teran MA, Hinchliffe JR, Ros MA. Birth and death of cells in limb development a mapping study. Dev Dyn 2006; 235: 2521-2537.

30. Montero JA, Ganan Y, Macias D, Rodriguez-Leon J, Sanz-Ezquerro JJ, Merino R et al. Role of FGFs in the control of programmed cell death during limb development. Development 2001; 128: 2075-2084.

31. Macias D, Ganan Y, Sampath TK, Piedra ME, Ros MA, Hurle JM. Role of BMP-2 and OP-1 (BMP-7) in programmed cell death and skeletogenesis during chick limb development. Development 1997; 124: 1109-1117.

32. Merino R, Ganan Y, Macias D, Economides AN, Sampath KT, Hurle JM. Morphogenesis of digits in the avian limb is controlled by FGFs, TGFbetas, and noggin through BMP signaling. Dev Biol 1998; 200: 35-45.

33. De Cat B, Muyldermans SY, Coomans C, Degeest G, Vanderschueren B, Creemers J et al Processing by proprotein convertases is required for glypican-3 modulation of cell survival, Wnt signaling, and gastrulation movements. J Cell Biol 2003; 163 625-635.
34. Hartwig S, Hu MC, Cella C, Piscione T, Filmus J, Rosenblum ND. Glypican-3 modulates inhibitory Bmp2-Smad signaling to control renal development in vivo. Mech Dev 2005; 122: 928-938.

35. Wu Y, Zhou BP. Snail: More than EMT. Cell. Adh Migr 2010; 4: 199-203.

36. Kawakami Y, Rodriguez-Leon J, Koth CM, Buscher D, Itoh T, Raya A et al. MKP3 mediates the cellular response to FGF8 signalling in the vertebrate limb. Nat Cell Biol 2003; 5: 513-519.

37. Lorda-Diez Cl, Montero JA, Diaz-Mendoza MJ, Garcia-Porrero JA, Hurle JM. Defining the earliest transcriptional steps of chondrogenic progenitor specification during the formation of the digits in the embryonic limb. PLOS One 2011; 6: e24546.

38. Saunders JW Jr.. The proximo-distal sequence of origin of the parts of the chick wing and the role of the ectoderm. 1948. J Exp Zool 1998; 282: 628-668.

39. Tabin C, Wolpert L. Rethinking the proximodistal axis of the vertebrate limb in the molecular era. Genes Dev 2007; 21: 1433-1442.

40. Rowe DA, Fallon JF. The proximodistal determination of skeletal parts in the developing chick leg. J Embryol Exp Morphol 1982; 68: 1-7.

41. Dudley AT, Ros MA, Tabin CJ. A re-examination of proximodistal patterning during vertebrate limb development. Nature 2002; 418: 539-544.

42. Maurin JC, Couble ML, Didier-Bazes M, Brisson C, Magloire H, Bleicher F. Expression and localization of reelin in human odontoblasts. Matrix Biol 2004; 23: 277-285.

43. Sato N, Fukushima N, Chang R, Matsubayashi H, Goggins M. Differential and epigenetic gene expression profiling identifies frequent disruption of the RELN pathway in pancreatic cancers. Gastroenterology 2006; 130: 548-565.

44. Khialeeva E, Lane TF, Carpenter EM. Disruption of reelin signaling alters mammary gland morphogenesis. Development 2011; 138: 767-776.

45. Yuan Y, Chen H, Ma G, Cao X, Liu Z. Reelin is involved in transforming growth factor-beta1-induced cell migration in esophageal carcinoma cells. PLOS One 2012; 7 : e31802.

46. Garcia-Miranda P, Vazquez-Carretero MD, Sesma P, Peral MJ, llundain AA. Reelin is involved in the crypt-villus unit homeostasis. Tissue Eng Part A 2013; 19: 188-198.

47. Zuzarte-Luis V, Hurle JM. Programmed cell death in the embryonic vertebrate limb. Semin Cell Dev Biol 2005; 16: 261-269.

48. Barrallo-Gimeno A, Nieto MA. The Snail genes as inducers of cell movement and survival: implications in development and cancer. Development 2005; 132: 3151-3161.

49. Beffert U, Morfini G, Bock HH, Reyna H, Brady ST, Herz J. Reelin-mediated signaling locally regulates protein kinase B/Akt and glycogen synthase kinase 3beta. J Biol Chem 2002: 277: 49958-49964.

50. Simo S, Pujadas L, Segura MF, La Torre A, Del Rio JA, Urena JM et al. Reelin induces the detachment of postnatal subventricular zone cells and the expression of the Egr-1 through Erk1/2 activation. Cereb Cortex 2007; 17: 294-303.

51. Herz J, Chen Y. Reelin. lipoprotein receptors and synaptic plasticity. Nat Rev Neurosci 2006; 7: 850-859.

52. Sekine K, Kawauchi T, Kubo K, Honda T, Herz J, Hattori M et al. Reelin controls neuronal positioning by promoting cell-matrix adhesion via inside-out activation of integrin alpha5beta1. Neuron 2012; 76: 353-369.

53. Bang OS, Kim EJ, Chung JG, Lee SR, Park TK, Kang SS. Association of focal adhesion kinase with fibronectin and paxillin is required for precartilage condensation of chick mesenchymal cells. Biochem. Biophys Res Commun 2000; 278: 522-529.

54. Choi YA, Kim DK, Kang SS, Sonn JK, Jin EJ. Integrin signaling and cell spreading alterations by rottlerin treatment of chick limb bud mesenchymal cells. Biochimie 2009; 91 : 624-631.

55. Rokutanda S, Fujita T, Kanatani N, Yoshida CA, Komori H, Liu W et al. Akt regulates skeletal development through GSK3, mTOR, and FoxOs. Dev Biol 2009; 328: 78-93.

56. Zheng Y, Gierut J, Wang Z, Miao J, Asara JM, Tyner AL. Protein tyrosine kinase 6 protects cells from anoikis by directly phosphorylating focal adhesion kinase and activating AKT. Oncogene 2012; e-pub ahead of print 1 October 2012; doi:10.1038/onc.2012.427.

57. Miner JH, Cunningham J, Sanes JR. Roles for laminin in embryogenesis: exencephaly, syndactyly, and placentopathy in mice lacking the laminin alpha5 chain. J Cell Biol 1998; 143: 1713-1723.

58. Bose K, Nischt R, Page A, Bader BL, Paulsson M, Smyth N. Loss of nidogen-1 and -2 results in syndactyly and changes in limb development. J Biol Chem 2006; 281 39620-39629

59. Katsuyama Y, Terashima T. Developmental anatomy of reeler mutant mouse. Dev Growth Differ 2009; 51: 271-286.

60. Zhang QC, Petrey D, Garzon JI, Deng L, Honig B. PrePPI: a structure-informed database of protein-protein interactions. Nucleic Acids Res 2013; 41: D828-D833.

(c) (1) $\Theta$ Cell Death and Disease is an open-access journal published by Nature Publishing Group. This work is licensed under a Creative Commons Attribution-NonCommercialNoDerivs 3.0 Unported License. To view a copy of this license, visit http://creativecommons.org/licenses/by-nc-nd/3.0/ 